Revista de la Facultad de Medicina de la Universidad de lberoamérica

\title{
(2) MEDICINA
}

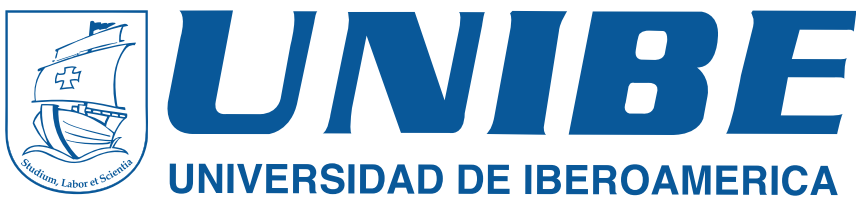

\section{Articulo}

\section{Recocimiento de Electrocardiograma}

\author{
Dr. Andres Cairol Barquero \\ Coordinador del Centro de entrenamiento en Reanimación- UNIBE \\ Correspondencia: acairol@unibe.ac.cr
}

\section{Caso clínico}

Paciente masculino de 52 años, conocido hipertenso, cardiópata, con antecedente de haber tenido un infarto agudo al miocardio hace 6 años, el cual hace 4 días fue sometido a una intervención quirúrgica para la colocación de un cardio desfibrilador. A su llegada al servicio de emergencias refiere que siente dolor en el sitio de la incisión donde le colocaron el desfibrilador y que además tiene leve dificultad para respirar. Es clasificado como CTAS II según la escala canadiense de triage y es valorado de manera inmediata por un médico el cual en el examen físico encuentra: paciente sin datos de dificultad para respirar, dolor en el sitio quirúrgico, más no en el resto del tórax, consciente alerta, a la auscultación cardiaca presenta ruidos cardiacos con una frecuencia muy elevada y no se logra distinguir ningún soplo. Presenta murmullo vesicular normal y no hay datos de ruidos agregados. Los signos vitales al ingreso son: frecuencia cardiaca en 220 y sube a 250 por minuto, frecuencia respiratoria en 18, Presión arterial 96/ 50 $\mathrm{mmHg}$.

El médico le realiza un electrocardiograma, ¿qué se puede observar?
Figura 1. Electrocardiograma realizado al ingreso del paciente al servicio de emergencias.

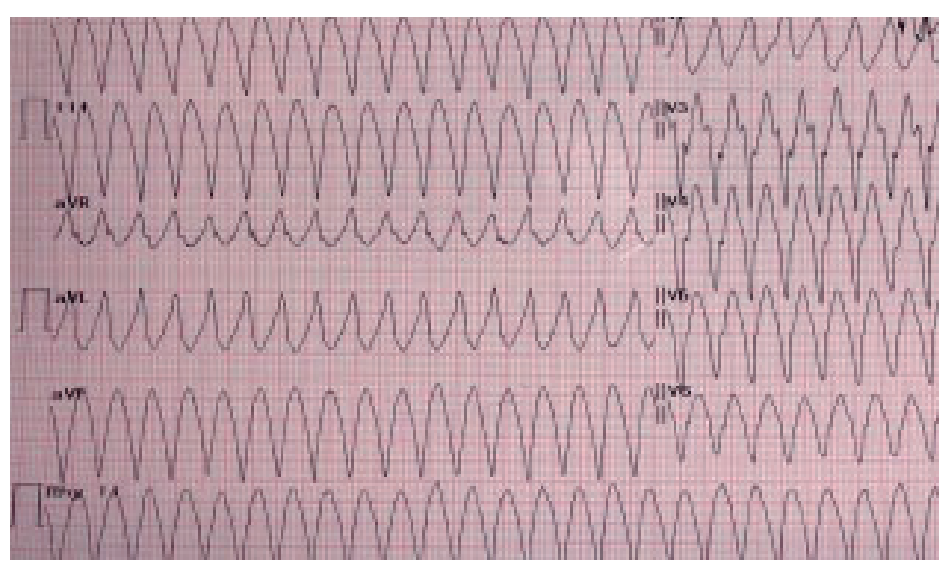

\section{Respuesta}

El electrocardiograma muestra ausencia de la onda $\mathrm{P}$ en todos los complejos, por esta razón no se puede afirmar que el paciente es portador de un ritmo sinusal. La frecuencia cardiaca es de 250 / minuto, la cual fue calculada de la siguiente manera: debe contar la cantidad de cuadros pequeños que se encuentran entre una $R$ y otras R. Posteriormente toma el valor 1500 $\mathrm{y}$ lo divide entre la cantidad de cuadros pequeños que calculó anteriormente. Por ejemplo, en este caso, 1500 entre 6 cuadros pequeños que hay entre $R$ y $R$, lo que da como 
resultado 250. Los complejos que se observan son anchos (QRS > 0,12 segundos), aspecto que hace pensar que el trazo observado proviene del ventrículo. Al final de la evaluación, tenemos un trazo que muestra ausencia de la onda $\mathrm{P}$, QRS mayor a 0,12 segundo el cual es regular entre cada una de sus $R$ y $R$, ya que un $Q R S$ mayor a 0.16 segundos es sugestivo de Taquicardia Ventricular (TV) (1). Por todos estos hallazgos electrocardiográficos, el paciente lo que presentaba es una taquicardia ventricular monomórfica, ya que todos los complejos con iguales.

\section{Referencias}

1. Wellens H. Electrophysiology: Ventricular tachycardia: diagnosis of broad QRS

complex tachycardia. Heart. 2015; 86(5):579-585.

2. Letsas K, Efremidis M, Manolatos D, Sideris A. Narrow QRS Complex Tachycardia Inducing Wide QRS Complex Tachycardia: What Is the Mechanism?. Pacing and Clinical Electrophysiology. 2016;33(5):615-617. 